\title{
Motivation Forms Regarding the Pro-Social Behaviour of the Teenagers at School.
}

\author{
Authors: Esjurda TALLUSHIํㅡ, Gjylse BIBA¹, Temisa ISUFI ${ }^{1}$
}

\begin{abstract}
Teenagers are considered a vulnerable group, not only due to the characteristics of their age, but also due to the high risk of their involvement in asocial behavior, as a result of many social problems, duality of values, confusion regarding decision-making at an early age, the absence of positive models to follow, not only at school, in the community, but also within their family.

In the Albanian reality particularly, the building of self-esteem is not the only influencing element, in the formation of the concept on oneself, and the concept of personality, but also the frustration of a society, that has gone through a long period of transition, the aftermath of a dictatorship. On these grounds, the motivation forms of positive behavior have been influenced by the family authority, rule obedience as an escape from punishment, and not as a result of awareness, reward, and proper methods of teaching in schools.

The aim of this work is to explore the motivation forms of the pro-social behavior, for the purpose of avoiding asocial behavior of teenagers in schools, via the effective communication, positive models, constructive teaching methods, proper parenting styles, socializing processes, removal of attention from asocial behavior and the providing of proper models to follow.

The method used in this work will be the mixed research (qualitative and quantitative). Part of this study will be teenagers aged 15-17 years old (boys and girls) of a high school in the city of Kavaja (Albania) through filling out half structured questionnaires. We have interviewed also professional teachers, parents, social workers and psychologists, in order to provide a clear panorama of this context, by analyzing with existing cases and well determined intervention that bring forth a strengthening of positive behaviors and avoidance of asocial behaviors in teenagers.

The findings of this study are closely related with the importance of any form of motivation in schools, in the teacher-teenager relationship, cooperation between their peers, the parent-teenager relationship in the implementation of the resulting positive attitude, through teaching a system of values and anti-values, the psycho-social motivating intervention during the teaching process that will be widely analyzed and that open many paths for further studies.
\end{abstract}

Key words: teenager, pro-social behavior, motivation, teacher, psycho-educational intervention, communication, parent, socialization.

\section{Introduction}

School adolescents face different challenges not only because of the difficult age period but because they socialize with deviant behavior peers. From the early age, when our personality hasn't taken the right shape, the parent imparts to the child moral values and principals other than social norms similar to a teacher guiding the pupil the process of reality perception and constructive communication of pro-social behavior.

Behavior is taught and as such it can be modified, untaught from negative to positive. This means that none of its components, communication, attitude, adaptation and 
action, should be underestimated. Pro-social expressions which we use are not acquired only by models which we had, but they are acquired by early learning in schools in the right manner inscribing on us the behavior and its prototypes.

The attitude that society and mainly the school holds, is not always active in promoting accepted social behavior at adolescents. This happens because of the absence appropriate psycho -social methods and professional supervision for modification of approach, behavior or communication parent-adolescent-teacher. This trinomials dysfunction becomes more visible in societies where the parents and teachers are themselves formed and raised under dictatorial system or through the transition period between dictatorship and democracy. The duplication of values, the void parental support and especially teacher's new social problems like the danger of using narcotics, bullying, youth criminality, and their request for freedom was answered total indifferentism or with total control which made the youth to close even more on themselves.

Peer influence and the adaptation of new behavior, not always positive, brought up the need of their prevention and injection of pro-social forms, motivation of accepted behavior and minimizing dangerous attitudes. This approach is pointed out through the professionals' specialized viewpoint, subjective thoughts of parents and directly from the adolescents.

\section{Methodology}

Object of Work: the purpose of this study is the exploration of motivation forms of pro-social behavior in order to avoid in schools adolescents' antisocial behavior through effective communication, positive role models, constructive teaching methods, adequate parentage styles, socializing process, avoiding attention from asocial behavior and offering positive role modeling.

\section{Specific Objectives:}

Offering a clear picture adequate motivation forms of pro-social behavior.

Recognizing psycho-social methods to minimize adolescents' asocial behavior

To point out the importance of positive and supportive role modeling by teachers, social workers, psychologists, parents, peers and community

Hypotheses: If school adolescents are motivated through the right psycho-social methods by professionals like; teachers, psychologists, social workers and parents for pro-social behavior then the asocial behavior will minimize, modify in to acceptable behavior.

\section{Methodology:}

The used method in this work will be a mix search (a conjuncture between quality and quantity research). Part of this study will be about 200 adolescents of the age between 15-17 year olds (boys and girls) of a high school in the town of Kavaja Albania. The sectioning of this town was done to enable a fair representation of all social layers in difference to social-economic and cultural-educational life offered in a metropolitan city. 200 students are selected randomly in 20 classes through the registry $(5$ girls and 5 boys in each class) from first year in to the third year high school. Then, a semi structured questionnaire is filled through second and third week of March 2016. Also, during this time, interviews with professionals have taken please such as; 10 teachers of different 
subjects to find general information about identifying asocial behavior, their prevention, and pro-social behavior motivation manners; 10 parents in order to understand their perception of what adolescents risky behavior is. During this period have taken place to find a more specialized information about the situation we interviewed 6 social workers and school psychologists of the same county (two of high school and four of 9-year education school<primary and secondary> of Kavaja county) to bring a clear view of this context through analyzing and concrete cases and well-thought intervention which reinforce positive behavior and avoiding asocial adolescents' behavior. All the study participants took part in this study voluntarily.

\section{Study Limits:}

This study can not be generalized for the whole country, as the social-economic and cultural reality changes to a greater variation from rural to urban areas.

The study subjects (adolescents, professionals, teachers, parents) selected, are not a considerate number to express a concreate stature against asocial behavior and the motivation of pro-social behavior in schools.

Also, the adolescent period in schools is confined between the high school years subject group between 15-17 year olds, meanwhile this age group is much wider.

\section{Used terminology}

With adolescents in our study we will refer the age when legal responsibility starts and when the adolescent is treated as an adult meaning 14-18 years even-though this age group goes up to 22-23 years of age.

Motivation is represented by the forces which act upon or within the person and which make him/her to behave in a certain manner oriented by known objectives.

The Behavior which promotes wellbeing is the behavior which facilitates the situation where the adolescent is explained in a simple, understandable language and helps the adolescent to identify strong points and the resources which are needed to overcome the situation; and reinforces or develops new sources where he/she can feel safe and far rom problems and criminality.

\section{Literature used}

Locke's (1968) work consists on the idea that one individual is motivated when we put him/her through clear objectives and when we use the right comment for his/her capacity and achievement. In the motivation field there are several classical consolidated theories which are published round 50s of last century, theories which have inspired more modern theories and they stand at the foundation of the later ones. One of the most important theories is that of A. Maslow known as the theory of the "hierarchy of needs". Other theories are theories $\mathrm{X}$ and $\mathrm{Y}$ followed by the theory Z, theory of dual factors (hygiene motivation) etc.

Being essential factor in to modifying the asocial behavior in to pro-social are teachers, based on 1995 work of Fuller and Bowen refined the theory of anxiety. They identified three anxiety phases through which teachers encounter during their development, where the third one is connected with the way of treating and motivating the adolescents and which is named as the influential anxiety.(worries about students/ pupils, their learning, their progress and the way teachers can increase this progress ae. By knowing and 
understanding their social and emotional needs, being fair to all students, by recognizing the individual effect of teaching at one individual, and by individualizing teaching through selection of content to maximize the intellectual and emotional increase, based on learning and the students' motivation problems).

A strong point in relationships between pupil/student-teacher is constructive communication and working with the parents or carers. In the $17^{\text {th }}$ century Comenius and Froebel in the $18^{\text {th }}$ century, pointed out the obvious relationship between school and family ${ }^{1}$. It has been noticed that overprotection and control of teachers are dominant features of the teachers of these adolescents, something that apparently creates a vicious cercus and feeds the anxiety on them. Bullying comes from transferring of compressed feelings and the exposure to different situation containing family violence. Teachers have to be involved in the pupils/students learning process ${ }^{2}$. Teachers should be aware of pupil/student individual changes and on these basis to develop their work.

\section{Analysis and interpretation of data:}

Results from the semi-structured questionnaires completed by teenage students:

When being asked the open question of what causes problematic behavior among teenage students, the most frequents answers were: conflicts with parents, teachers and peers; bulling and the tendency of dominance; insufficient academic achievement and the usage of alcohol and other different narcotic.

$>\quad$ To the question what bothers you most in your everyday life, they responded a- 32\% Family b - 38\% Schools c - 30\% Relations with their peers

From the result provided, it could be easily noticed that the three components (family, school, friendship) are almost of the same importance for a teenage well-being and serenity. The minimization of the stress in any of these targets would no doubt contribute positively for the teenage discipline and positive behavior.

$>\quad$ Their expectations about the future can be can be found out by analyzing the way they have answered to the question: how do they expect their future to be:

a $-45 \%$ very difficult b-30\% successful c- $25 \%$ don't think at all about their future

From these responses it is impressive the fact that, despite the high inspirations that naturally categorizes this target group, teenage tend to see their future with pessimism and lots of insecurities, which may later lead to uncontrolled negative behavior.

To the question: Who do they most share their problems with, they answered: a- $25 \%$ family member $\quad$ b $-18 \%$ the psychologist / social worker

$$
\text { c- } 15 \% \text { Teachers / s d- } 30 \% \text { their friends e - } 12 \% \text { no one }
$$

From responses, it is noticed that peers are those who influence most in a teenager`s life and decision-taking. Friends are more influential than even their family members as they are regarded more reliable, while among family members, there is noticed lack of

1 Comenius, J.A.(1967) The Great Didactic (Didactica Magna) by John Amos. New York: Russell\&Russell fq.33

2 Instituti I Kurrikules dhe I Trajnimit, Standartet e mësuesit, Drejtuesit, trajnerit, Tiranë, 2008, fq. 10,26 
communication. Surprising is the percentage of introverted teenagers, who lack the communication with anyone. The percentage of teenagers who communicate with teachers and especially social workers or psychologist is quite promising and in contrast to the past. This shows that teenagers are appreciating and becoming more aware about the importance of accepting specialized assistance for personal problems.

\section{answered:}

When being asked if they knew any of their peers who showed bulling behavior, students

\section{a- $40 \% \quad$ Yes b- $60 \%$ No}

A significant percentage of adolescents have admitted that they know bullies, which means that these "negative influential" elements are present at school environment.

$>\quad$ To the question whether they have ever been informed of any case when their peers may have been evolved in any criminal or deviant behavior, they answered: :

a- $28 \%$ Yes b- $72 \%$ No

o If yes, do they know any what measures have been taken by the school toward these individuals?

Some of the responses were that they had no information about what happens to those individuals. Some of them mentioned cases that were offered specialized and professional assistance (such as that of social worker or psychologist); cases when was offered family or relative assistance and some desperate cases when the individuals were excluded from school and friends. On the other hand, there were even some cases which were offered the strong assistance of their classmates and teachers, and they had successfully overcome the situation.

To the question whether the negative behavior could be completely cured or at least minimized, students answered:

a-yes $55 \%$

b- $45 \%$ no

Most of students supported the idea that teenagers with problematic behavior could be managed and improved with the help of professional assistance (of psychologist or social worker) and precious support of family-school-friends.

o If yes, how can it completely be cured?

Some who were in favor added that despite the professional assistance, crucial was the support that those individuals must have from the society as a whole. Instead of being excluded, they must be supported and not being prejudiced. They must praise and appreciated for each every advancement they do in their behavior. Of a great help would also be the raising of their awareness regarded to the consequences and the risk that drug brings to them.

To the question what motivates e teenager to maintain a positive behavior and avoid the negative, most of the students mention the role of family helping the child to gain selfconfidence, encourage the feeling of responsibility in them, implying a positive attitude toward life and their future, pursuing different entertaining activities such as sport or other hobbies, a good and respected reputation among their peers, volunteering etc.

Results collected from the interviews done with psychologist, social worker and teachers. $>\quad$ When being asked the open question of which are the factors that cause antisocial and deviant behavior among adolescents, they answered: 
Most of them highlighted the dependence that teenagers have acquired to smoking, alcohol, drugs; deviant behaviors they engage time after time and problems with low. Other mentioned the lack of communication that are present in Albanian families and some schools; eating and sleeping disorders which quite often cause health problems; social problems such as parents divorce, economic problems, bulling and lack of appreciation by their dearest etc. All those factors directly lead to crises of adolescence, when not accurately treated or overcome, influence negatively to teenager's psychological and emotional wellbeing.

\section{Discussion}

A considerate number of cases delinquency of adolescents or minors is proceeded from antisocial behavior enacted as an aggressive behavior, tendencies of destroying the surrounding, stealing, lying etc. Some sociologists and psychologists even talk for pre-delinquent behavior to define foreign behavior likely to accompany a delinquent behavior. Usually, such behavior is motivated from the social surroundings or pre-delinquent's family. (QSHRT, 2004). D.W. / Winnicott has written "(at the core of any antisocial behavior is a void, an absence..... An antisocial child seeks that, in one way or in one other, gently or violently the world should know the debt that owes to $\mathrm{him} /$ her, or by trying to make the world repair what it* has destroyed (Weinnicot, 1957). Contemporary pedagogy, stretches out the importance of preparation on cultural knowledge and teacher's communicative abilities to analyze class situations ${ }^{3}$. Often is discussed about the curriculum and the methods which have in their center the pupil/student, different learning manners but rarely teachers talk about the pupil/student, their values and the fact that they deserve to be treated with respect. According to Durkheim, the main reason for low achievements in school is poor communication and motivation between pupil/student and teacher ${ }^{4}$. Regardless of their work that teachers do with the pupils/students, other studies show that the levels of motivation other than teachers' professional competences, play the most important role in the learning process.

Part of socio-psychology services in aid of vulnerable children and individuals are psychologists and social workers who serve as changing agents through the increase of human capacity to solve social problems and to help face difficult situations by referring people with social systems which secure resources, services and opportunity which promote effective human systems ${ }^{5}$.

Study findings are connected with the importance of any motivational form in schools and in the relation adolescent-teacher, peer interaction, relations between the adolescent and the parent in the injection of a consequent positive attitude, through education and a system of values and anti-values, psycho-social motivational interferences through the teaching process which will be widely analyzed and will open a way for further studies. The model offered from people which are part of adolescents' school life is very

\footnotetext{
3 Instituti i Kurrikules dhe Trajnimit, Revista Pedagogjike 3, Tirane 2008.fq.116-117

${ }^{4}$ Durkheim, E.,(1971), La sociologia e l'educacione. New Town Compton Italiano, fq.24

${ }^{5}$ Gibelman, Margaret. Punonjesit Sociale. Fq 19. Tabela 1
} 
important. Sociologists say that the culture gained through education is the property and the best human investment, because it gives him/her an educated approach in all fields of life ${ }^{6}$. In this context known philosopher Ernest Gellner, as the master of anatomy and modern role of education institutions thinks that: "Most hidden human identity is not defined by his bank statements nor by his relatives or his status but by his schooling culture"7 Socio-economic factors play a very important role in adolescents non fitting environment. Deep socio-cultural changes can lead to a disorientation of adolescentparent relationship weakening the family values and the adaptation of youth the defensive positioning, non-tolerant and aggressive and the increase of the importance of the outer-family groups which encourage different aspirations from the adults.

Peer groups play a primary role. Their influence is dominant and often much stronger than family influence.

Motivational interviewing as the psychologist's method and the social worker's has the objective to cause a change of behavior, a change which the adolescent because of his natural tendency wouldn't have achieved. This method has the aim to facilitate, stimulate and cause behavior change by helping the clients to explore and resolve their uncertainties. To change behavior from behavior in only few manners to behavior in different manners. To change interests, from shallow and irregular into deep and constant. To change orientation from "only today" to "the past" and to the "today and the future". To change his/her perception from his absence to understanding clearly and fully to him/herself and to be in continues control of it.

To treat problematic adolescents is important the facing the facts which helps the adolescent to change and grow. Whereas other expressions help the child to ease the situation, to give $\mathrm{him} /$ her a support in to changing, is the facing with their inconsistencies which acts as a boost in the activation of their true potential. The identification of adolescent's inconsistencies mix messages and possible conflicts are confronted with the adolescent who is encouraged to talk in details and to resolve his problems. Facing is not going against the adolescent but to walk in the same step as he is, to ask for clarity and possibly a difficult solution.

\section{Conclusions:}

Non-focusing in asocial behavior, not-criticizing, not-augmenting of situations does not help the injection of the pro-social behavior. Motivation for pro-social behavior should be introduced with the right methods and the right psycho-social constructive expressions which do not demotivate, punish or blame the adolescent but through a strong and supportive system give him a window of opportunity for the future, where he can walk and progress and modify his challenging behavior into an acceptable behavior, to reflect in relation to his action, verbal and nonverbal behavior and through different alternatives to channel his aggressive, deviant or delinquent behavior. The creation of the new social vulnerable groups, requires a quick and effective response using the

${ }^{6}$ Giddens, A.,(2006)Sociology (fifth edition). Polity Press, Cambridge, UK, fq.6

7 Gellner, E.,(1994)Conditions of liberty:civil society and it's Rivals, Hamish Hamilton Ltd, fq. 179 
appropriate policies, using and developing the professional institutional governmental and civic capacities.

\section{Recommendations}

To determine plans and long term strategies of school professionals and their supervisors to include as many adolescents as possible in peer education school groups, groups of peer awareness, and interactive groups organized by them where the trust of treating these phenomenon increases

The parent to be approached more through activities but using the professionals support as well so the adolescents' problems to be detailed in order o intervene in the right manner.

It is required greater attention of community of the governmental structures and NPO in support of adolescents who don't only have the psycho-social problems but family problems as well.

It is very important the approach of a model which offers solution for the conflicts and the misunderstandings with an intermediate where the adolescents, teachers, parents, are involved.

Subjects in whom we discuss mainly social expressions for daily and life purpose to be given a greater importance, according to the manner in which their realization of curricula can be possible.

\section{References}

-QSHRT, (2004). Sjelljet delinkuente. Suplement.Vol 3, 27-28.

-Giddens, A.,(2006)Sociology (Fifth edition). Polity Press, Cambridge, UK, fq.6

-Gellner, E., (1994)Conditions of Liberty:civil society and it's Rivals, Hamish Hamilton Ltd,fq.179

-Instituti I Kurrikulës dhe Trajnimit, Revista Pedagogjike 3, Tiranë, 2008, f.116-117

-Durkheim, E., (1971), La sociologia e l'educazione, Neë toun Compton Italiano, fq.24

-Gibelman,Margaret.punonjësit Socialë.fq 19 .Tabela 1

-Comenius,J.,A.(1967)The Great Didacti (Didactica Magna)by John Amos.NeëYourk:Russell\&Russell fq.33

-Instituti i Kurrikules dhe i Trajnimit,Standartet e mësuesit, Drejtuesit, trajnerit, Tiranë, 2008,fq.10, 26. 